\title{
The Management of Pulmonary Tuberculosis in Chest Clinics
}

\author{
J. M. weddell, M.B., B.S \\ Children's Wing National TB Sanatorium, Masan.
}

The management of pulmonary tubercaulosis centres round the chest clinics and in Great Britain these look after the great majority of patients in the country. Each clinic serves a defined area, the population of which varies from about 3,000 to 5,000 .

Patients are referred to the clinics by their own doctors, by Mass Radiography Units, by their own firms and the school medical officers.

The chest clinic staff is made up of doctors, nurses who work entirely in the clinic, health visitors who work in the clinic and also carry out home visits, almoners. radiographers, and an occupational therapist; there is also an office staff whose principle job is to file the notes and X-rays correctly.

The clinic is not concerned soley with the treatment of tuberculosis, but with the re-establishment of the patient as a useful member of society, a much more complex job.

When a patient is referred to the clinic he has a chest $\mathrm{x}^{-r a y}{ }^{-}$is weighed, and is seen by a doctor. In some cases a diagnosis of pulmonary tuberculosis can be made immediately; it is of the utmost importance that the full confidence of the patient should de gained from the first interview, for this reason the position is explained to him carcfully, he is given some idea of the possible length of treatment though it is made clear to him that it is impossible to say exactly at the first visit how long the treatment will last; the type of treatment is disussed whether this will be ambulatory, whether he should go to bed at home or whether he will need admission to a sanatorium. The type of work he is doing is discussed, and the decision is made as to whether he will need to change to a lighter job or will need to sive up work altogether. The question of infection is discussed, it is explained, that the infection is spread by the sputum, the patient is instructed in the disposal of sputum, advised to have separate crockery, and to sleep in a separate bed and if possible in a separate room. If there are younger children in the house it is best that they should be segregated from the patient until it has been dotermined whether they are Tuberculin negative or positive, and the negative reartors have been given B. C. G. and have becoms Tuberculin positive. It is explained to the patient that it is important that as many people as possible who have been in contact with him should have their chests $x$-rayed to findout now many have been infected. It is important to obtain the cooperation of the patient over this matter as it is not possible to carry out a full contast investigation without it.

The necessary specimens are taken for pathological investigation: sputum or 1 ryngeal swabs, blood for B.S. R. haemoglobin and any other test: that are nece- 
ssary in each particular case.

The patient then visits the almoneer who deals with any financial problems that have arisen, explains to him the benifits to which he is entitled under the National Health and National Insurance schemes; if lighter work is suggested by the doctor the almoner will try to arrange this if this is not possible she will put him in touch with Labour Exchange, and the patient will be able :o find employment through them. In the case of the house-wile it may be necess. ary to provide her with home-help who will come and do some or all of the house work. The almoner will also arrange the boarding oar of children if this is needed.

All patients are visited at home by the health visitors, in the first week after the diagnosis of pulmonary tuberculosis has been made she will visit the patient two or three times to help both the patient and his family to make the adjust. ments required by the new situation. She makes sure that the patient understands what he has been told at the clinic, she impresses on the patient and his family the fact that they are not social outcasts, and emphasises the importance of the patient's own attitude to the situation and the fact that he can help himself in many ways, the most important of which is to cooperate with the clinic. If the patient is being treated at home she sees that the arrangement that has been made is adquate, that the patient will be able to rest and that the remainder of the tamily will be able to live a normal life in spite of the fact that there is an inv. alid in the house.

The treatment given varies considerably from the newly diagnosed active case to those who only need observation. Many patients are treated on an ambulant basis and receive their treatment while continuing to work; in some cases it is necessary to alter the type of work they are doing, either to do the same work $\mathrm{for}_{\mathrm{r}}$ shorter hours or to do lighter work altogether. These patients attend the clinic at regular intervals to be seen by the dnctor, to have chest $\mathrm{x}$-rays and for $\mathrm{sp}$ utum examination. Those patients who are treated at home have regular visits from the doctor and the health visitor, they are brought by ambulance to the clinic for $x$-ray, and if possible some occupation is found for them at home; some ciinics employ an occupational thera. pist who visits patients in their own homes and teaches them some suitable occipation. Admission is arranged for those patients in need of a sanatorium treatment. Those who need observation only, i.e, those with old lesions diagonsed by chance, are seen at the clinic at three monthly intervals then at longer intervals of six months and a yaar until it is telt that the disease is inactive. on return from sanatorium the cilnic supervises the up-grading of patients and their return to work it this is possible. Manypatients, on their return from sanatorium are frightened or unwillinng to take their place once more in the every day world and need a great deal of help and encouragement before they can settle down. The Disablement Rehabilitaton Officer will be able to place some in suitable jobs, other can be given training under a Government Training Scheme in light work such as watrh making, shoerepairing, or light factory work. Others 
may be able to return to their former jobs. Their medical progress is watched carefully at the clinic, and every patient is observed for a period of five years after the disease is inactive, i.e. after the sputum has become negative, the $B$. S. R. has been normal, their weight has remained steady, and there has been no change in the $\mathrm{x}$-ray for five years.

In every case the Contacts of each patient are investigated, their family, those with whom they work, either factory office or school. The contacts are seen at separate clinics to lessen the risk of

- infection; the most important groups to investigate are the children under five, and those between the ages of fifteen and twenty-five, as the incidence of infection is highest in these groups; these contacts have Tuberculin. Skin tests, the negative reactors are given B.C.G. and are segregated from the contact case until they have become Tuberculin positive. The contacts are then watched (usually for a period of two years) by $x$-ray only.

In addition the clinic runs a refill clinic for those who are receiving collapse therapy as out-patients, and carries out such out-patient treatment as injections and dressings. Many patients attend the clinic for a number of years and it is of the first importance that they should regard the staff of the clinic as their friends to whom they can come at any time for help and advice and to discuss any problem that is worrying them.

These remarks are based on my own observations and experiences, and are not meant to imply that every clinic in the country is run on presisely these lines, but I hope to bave given some idea of the work of the chest clinic. 